\title{
Integrated total cost and Tolerance Optimization with Genetic Algorithm*
}

\author{
R.Sampath kumar ${ }^{1}$, N. Alagumurthi ${ }^{2}$ \\ ${ }^{1}$ Research Scholar, ${ }^{2}$ Professor \\ ${ }^{1,2}$ Department of Mechanical Engineering, \\ Pondicherry Engineering College, Puducherry, India. \\ skum_7d@yahoo.com \\ R. Ramesh ${ }^{3}$ \\ ${ }^{3}$ Assistant Professor, \\ School of Mechanical Engineering, \\ SASTRA University, Tanjavur, India. \\ Received: 16-03-2009
Accepted: $08-12-2009$
}

\begin{abstract}
The tolerance allocation problem has been studied in the literature for decades, usually using mathematical programming (or) heuristic optimization approaches. Elegant tools for minimum cost tolerance allocation have been developed over several decades but still there is no specified tool to find the total cost with respect to machining cost and asymmetric quality loss functions. Objective of this paper is to find the optimized total cost by considering the machining cost and the asymmetric quality loss of an assembly. The non linear multi variable optimization of total cost problem formulated is solved using genetic algorithm. In this work, Piston and cylinder arrangement example was considered for concurrent allocation of design and machining tolerance, as well as to optimize the total cost. The result shows, optimized tolerance will enhances the quality and reduces the total cost
\end{abstract}

Keywords: Tolerance allocation, Machining cost, quality loss, Genetic algorithm.

\section{Introduction}

Tolerance is defined as the acceptable variation in the dimension of a geometric entity. The use of tolerance is unavoidable because in the manufacturing phase, a series of operations is applied to the components to control their geometry, size, location, variations in processes, materials, tool wear, fixture errors, setup errors, material property variations, temperature, worker skill, and so on, mean that parts can not be produced exactly.
Limits defining the tolerance are called tolerance or specification limits. The problem of setting these limits based on several criteria is known as tolerance design. The tolerance design is a key element for improving quality, reducing overall cost and there by helps retaining market share. Both design and manufacturing engineers have focused attention on the effects of variation of cost and performance of manufactured products. The tight tolerance are assuring fit and function of the assembly as required by the designer lead to higher cost for manufacturing and the loose tolerances which make parts easier and less expensive to produce lead to assembly problems and rejections. The demand for quality has focused attention on the 
effects on variation on performance of the manufactured products to achieve the robust tolerance design.

Many researchers have focused on the mathematical modeling of cost-tolerance relations and the optimization of related tolerances for minimum production costs [14]. A limited number of publications have tried to organize manufacturing costtolerance data obtained from machine shops and experiments and accordingly model the cost -tolerance functions [3]. Chase [16] used such data and obtained empirical functions for metal-removal process over the full range of nominal dimensions. The used original data was nevertheless old and may not be applicable to modern CNC machines.

\subsection{Tolerance allocation methods}

The rational allocations of component tolerance require the establishment of some rule upon which to base the allocation. The following are the types of methods for allocation of component tolerance [9, 27]: i. Allocation by proportional scaling, ii. Allocation by Constant precision factor, iii. Allocation by optimization techniques.

The first two methods, the name it self implies how to use these methods. The third one is a promising method which has been applied in this paper. In optimization technique various algorithm and tools are being used. The optimization algorithm varies the tolerance for each component and searches systematically for the combination of tolerances, which minimizes the cost.

In order to find the optimized total cost the paper is organized as follows. Broader literature review has been presented in section 2. In Section 3 various quality loss functions and its equations have given. A brief Introduction of the GA is given in section 4. Demonstration of the application of the GA on an example problem is presented in section 5. Section 6 deals with a brief discussion on the results. The work is concluded in section 7 .

\section{Literature review}

In practice, the empirical cost-tolerance data should be directly obtained from machine shops through experiments or observations, and recorded in the original form of discrete points. We assume the empirical data curves are composed of many closelyplaced data points, rather than results of interpolation or curve fitting. Discrete data points are picked up from these curves to direct model fitting and for fitting error analysis.

Chase and Greenwood [16] introduced the Reciprocal model with better empirical data fitting capability, considering both the continuous and discrete cost functions. Chase presented three methods-exhaustive searches, univariate search, and sequential quadratic programming-to solves the models originally proposed by Huang [5]. Nagarwala et al. [17] proposed a new slope-based method that took into account process selection.

Zhang and Wang [18], proposed mathematical models with the consideration of manufacturing process for continuous cost function and solved it first time by using non-traditional optimization technique called simulated annealing. Zhang [19] approached the problem in a totally different manner by introducing a new concept of interim tolerances, which help to determine appropriate manufacturing process and solved the problem using a non-linear programming technique (mixed penalty function approach). AlAnsary and Deiab [1] adopted a model similar to that proposed by Zhang and Wang [18] and solved the model by considering worst-case stack-up criteria using a genetic algorithm. Singh et al. [13] solved the same model for four different stack-up conditions using a genetic algorithm.

The quality loss function is used to determine the reduction in value due to an off target product, which is then balanced against reductions in manufacturing cost. Soderberg [20] developed a quality loss function based on component life time which represents the customer's objective.

Feng and Kusiak [21] considered quality loss in addition to manufacturing cost in a discrete cost function. Jeang $[6,22]$ developed a few general mathematical models to determine product tolerances minimizing the combined manufacturing costs and quality losses without considering the manufacturing processes, in a continuous cost function using quadratic and geometrical decay functions. Ye and Salustri [23] developed a simultaneous tolerance synthesis (STS) model with quality loss considering continuous cost function and solved using genetic algorithm. Conventional methods of tolerance analysis are inadequate for several reasons [24 - 26].

\section{Tolerance and Quality Loss Function}


Quality loss is one of the most important issues for quality engineering to evaluate the quality of the products or processes. Quality loss function is a quadratic expression estimating the cost of the average then comparing it to the customer identified target values and the variability of the product characteristic in term, of monetary loss due to product failure. The loss function $\mathrm{L}(\mathrm{y})$, indicates a monetary measure for the product characteristic value versus the target value. High quality and low cost are two fundamental requirements for product design and manufacturing. In an assembly, critical tolerance must be guaranteed for functional requirements [4-7].

Taguchi has suggested that the tolerance should be determined by trading off quality loss and cost [2]. A quadratic function shown in figure 1 could provide estimation for the economic loss. Taguchi also proposed the use of a loss function composed of two segments [2]. As shown in figure 2 two segments associated with different constant ' $k$ ' connect with each other at the design target the quality loss equals zero. Excluding the effects due to the manufacturing cost, the tolerance design can be derived from the trade-off between the extra cost of the disqualified products and the expected quality loss of the qualified products [2, $15]$.

\subsection{Variations of the quadratic loss function}

There is very important concept of quality engineering inherent in the loss function. In the usual practice of manufacturing quality control the producer specifies a mean value of the performance characteristic and the tolerance interval around that value.

Any value of the performance characteristic which falls within the interval is defined to be a quality product, even if it is barely inside the $-3 \sigma$ limit as shown in figure 3 . With loss function as a definition of quality the emphasis is on achieving the target value of the performance characteristic and deviations from the target value the greater the quality loss.

Types of loss function expressed as

i. Normal-the-best is the $L(y)=\frac{A}{\Delta^{2}}(y-m)^{2}(2)$

ii. Smaller-the -better is the $L(y)=\frac{A}{\Delta^{2}} y^{2}$

iii. Larger-the-better is the

$$
L(y)=A \Delta^{2}\left(\frac{1}{y^{2}}\right)
$$



Figure 1 Taguchi's loss function.

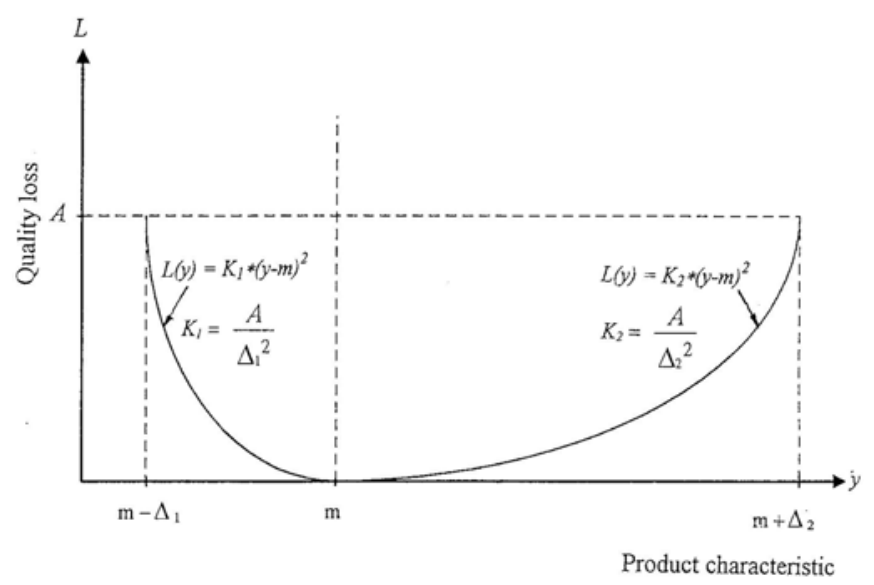

Figure 2 Asymmetric losses function.

In some situations, the quality loss resulting from deviation of quality characteristics in one direction is greater than the deviation in the other direction. In this case, various ' $\mathrm{k}$ ' values will be assigned for the two directions of the target $[6,11]$ as shown in Figure 2.

iv. The asymmetric quality loss function

$$
\begin{aligned}
& L(y)=K_{1}(y-m)^{2} y>m \\
& L(y)=K_{2}(y-m)^{2} y<m
\end{aligned}
$$




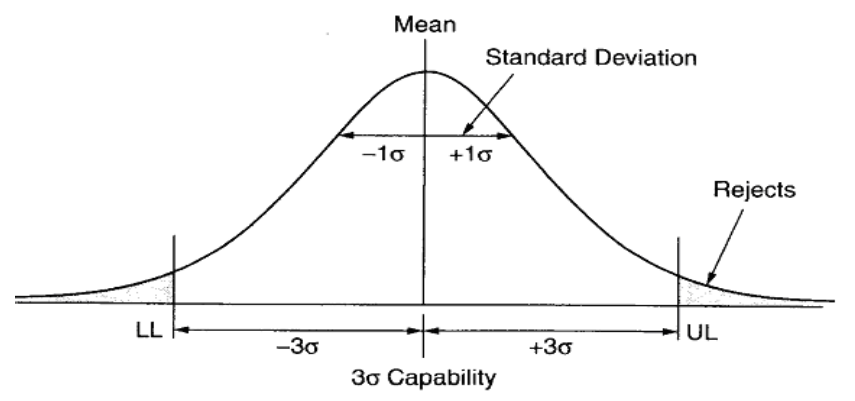

Figure 3 Frequency plot of size distribution for a process with random error

\section{Genetic algorithm a brief overview}

Genetic algorithms are good at taking larger, potentially huge, search spaces and navigating them looking for optimal combinations of things and solutions which has not been find in a life time [10].

\subsection{Basic concepts}

Genetic algorithms are very different from most of the traditional optimization methods. Genetic algorithms need design space to be converted into genetic space. So, genetic algorithms work with a coding of variables. The advantage [10] of working with a coding of variable space is that coding discredited the search space even though the function may be continuous. In GA uses a population of points at one time in contrast to the single point approach but in traditional optimization methods it is not so.

Three most important aspects of using GA are:

i. Definition of objective function

ii. Definition and implementation of genetic representation

iii. Definition and implementation of genetic operators.

Once these three have been defined, the GA should work fairly well beyond doubt.

\subsection{Working of Genetic algorithm}

GA is a very simple, straight forward, yet a powerful approach for global Search and optimization of multimodal functions. The approach combines the characteristics of direct search methods and probabilistic selection and is based on the mechanics of natural genetics and natural selection. It makes use of the robustness, Efficiency and flexibility of biological systems in to artificial ones. Different authors have explained useful schemes of the application of this approach. The working principle of GA is very different from that of the most of the classical optimization techniques. The distinguishing characteristics of the GAs are as follows [8].

i. Work with a coding of the parameter set, not the parameters themselves.

ii. Search from a population of points, not a single point.

iii. Use payoff (objective function) information, not derivative or other auxiliary Knowledge.

iv. Use probabilistic transition rules, not deterministic rules.

The general steps to be followed for implementing [12] simple GA for optimization Problems are listed below. However, note that they can be modified appropriately depending on the type and complexity of the problem. The steps are as follows.

Step 1. Coding of variables or representation of Solution.

Step 2. Selection of the population size, crossover probability, mutation probability, Genetic operators, number of generations, etc.

Step 3. Mapping of objective function into appropriate fitness function.

Step 4. Evaluation of each string to obtain fitness.

Step 5. Application of genetic operators:

(a) Reproduction on the population.

(b) Crossover on the random pair of strings, With specified probability of Crossover.

(c) Mutation of random bit, with specified Probability of mutation. Simultaneous optimal selection of design and manufacturing tolerances

Step 6. Repeat Steps 4 and 5 for the given number of generations.

\subsection{GA in tolerance formation}

In GA [9], a candidate solution is represented by a sequence of binary numbers known as chromosomes. 
A judiciously selected set of chromosomes is called the population and the population at a given time is called a generation. The population remains the same from generation and has a significant impact on the performance of the GA.

\section{Problem definition}

The problem taken for illustration is a Piston and cylinder assembly, which is given as a case study in [1, 13]. It is a simple linear mechanical assembly as shown in figure 4 involving only two components.

\subsection{Problem description}

To determine the optimal design and manufacturing tolerances for the Piston and cylinder assembly the details are as follows:

\section{Dimensions}

Piston diameter $\left(\delta_{p}\right): 50.8 \mathrm{~mm}$;

Cylinder bore diameter $\left(\delta_{c}\right): 50.856 \mathrm{~mm}$.

Clearance (x): 0.056 $0.025 \mathrm{~mm}$.

Machining process plan for the piston:

Rough turning $\left(\delta_{11}\right)$, finish turning $\left(\delta_{12}\right)$, rough

grinding $\left(\delta_{13}\right)$, and finish grinding $\left(\delta_{14}\right)$.

Machining process plan for the cylinder bore:

Drilling $\left(\delta_{21}\right)$, boring $\left(\delta_{22}\right)$, semi-finish boring $\left(\delta_{23}\right)$, and grinding $\left(\delta_{24}\right)$.

Thus, there are only two design tolerance parameters, one for the Piston diameter, the other for the cylinder bore diameter.

Also, there are four Machining tolerance parameters for machining each of the piston diameter and the cylinder bore diameter corresponding to the given process plans.

The Principal machining tolerances [1] in millimeters for the piston are

$$
\begin{array}{ll}
0.005 \leq \delta_{11} \leq 0.02, & 0.002 \leq \delta_{12} \leq 0.012 \\
0.0005 \leq \delta_{13} \leq 0.003, & 0.0002 \leq \delta_{14} \leq 0.001
\end{array}
$$

The Principal machining tolerances [1] in millimeters for the cylinder bore are

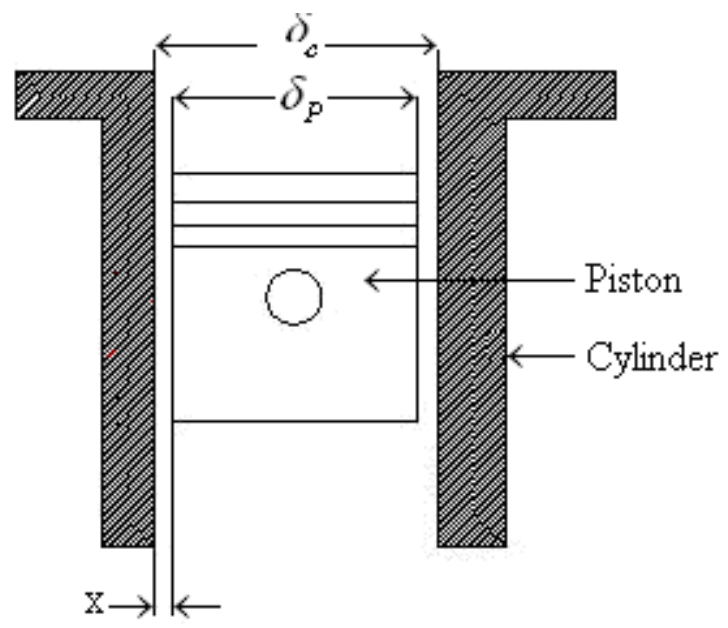

Figure 4 Piston and cylinder assembly

$$
\begin{array}{ll}
0.007 \leq \delta_{21} \leq 0.02, & 0.003 \leq \delta_{22} \leq 0.012 \\
0.0006 \leq \delta_{23} \leq 0.005, & 0.0003 \leq \delta_{24} \leq 0.002
\end{array}
$$

The total machining cost is determined by sum of the, machining cost-tolerance model equations for the eight machining processes of the piston-cylinder assembly. In general many cost tolerance models are in use, in this example the modified form the exponential costtolerance model was used to find the machining cost is as follows.

The form of exponential cost-tolerance model [1] used, $\mathrm{g}(\delta)$, is expressed as

$$
g(\delta)=\frac{c_{0}}{e^{c_{1}\left(\delta-c_{2}\right)}}+c_{3}
$$

The total machining cost, $\mathrm{c}_{\mathrm{m}}$, is expressed [1] as

$$
c_{m}=g_{11}\left(\delta_{1}\right)+g_{12}\left(\delta_{2}\right)+g_{13}\left(\delta_{13}\right)+g_{14}\left(\delta_{4}\right)+g_{21}\left(\delta_{21}\right)+g_{22}\left(\delta_{22}\right)+g_{23}\left(\delta_{23}\right)+g_{24}\left(\delta_{24}\right)(9)
$$

The coefficients values for the cost-tolerance function of equation (9) are given in Table 1.

\subsection{Constraints}

The constraints on the principal design and machining tolerances are [1].

i. The sum of the design tolerances of piston and cylinder bore diameter should be less than (or) equal to the clearance tolerance 


$$
\delta_{11 d}+\delta_{21 d} \leq 0.001
$$

ii. The design tolerance for a given feature of a part is equal to the finial machining tolerance.

$\delta_{11 d}=\delta_{14,}$ For the piston and $\delta_{21 d}=\delta_{24}$

iii. The sum of the machining tolerance for a process and the preceding process should be less than or equal to the difference of the nominal and minimum machining allowances for the process. For the piston

$\delta_{11}+\delta_{12} \leq 0.02, \delta_{12}+\delta_{13} \leq 0.005, \delta_{13}+\delta_{14} \leq 0.0018($

12)

For the Cylinder

$\delta_{21}+\delta_{22} \leq 0.02, \delta_{22}+\delta_{23} \leq 0.005, \delta_{23}+\delta_{24} \leq 0.0018$

The Design tolerances are framed by four stacked up conditions are Worst case, RSS, Spotts and estimated mean shift criteria. These stack-up conditions yield a set of design constraints as below:

Worst case criteria $=\delta_{14}+\delta_{24} \leq 0.001$

RSS criteria $=\delta_{14}^{2}+\delta_{24}^{2} \leq(0.001)^{2}$

Spotts $=\frac{1}{2}\left[\left(\delta_{14}+\delta_{24}\right)+\sqrt{\left(\delta^{2}{ }_{14}+\delta^{2}{ }_{24}\right)}\right] \leq 0.001$

Estimated mean shift criteria $=$

$\left(m_{1} \delta_{14}+m_{2} \delta_{24}\right)+\frac{Z}{3} \sqrt{\left[\left(1-m_{1}\right)^{2} \delta^{2}{ }_{14}+\left(1-m_{2}\right)^{2} \delta^{2}{ }_{24}\right]} \leq 0.001$

The total machining cost is optimized subject to the constraints and the ranges of the principal design and machining tolerance mentioned above. The genetic algorithms method has been used as an optimization engine. In the optimization process using the genetic algorithms method, binary representation is employed with an individual length of 80 bits for the eight variables of the design space.

Populations size will be of 20 with 100 generations were used with the binary tournament selection method. These parameters were selected by tuning the genetic algorithms method around the values suggested by Al-Ansary [1]. The results are discussed in section 6 . The total cost is obtained by adding the machining cost $g(\delta)$ and asymmetric quality loss function L(y).
Table 1 Coefficients Parameters for the eight machining processes [1]

\begin{tabular}{|c|c|c|c|c|c|c|c|c|c|}
\hline $\begin{array}{l}\mathrm{N} \\
\mathrm{O}\end{array}$ & $\begin{array}{l}\text { Co } \\
\text { effi } \\
\text { cie } \\
\text { nts }\end{array}$ & $\begin{array}{l}\mathbf{g}_{11} \\
\delta_{11}\end{array}$ & $\begin{array}{l}\mathbf{g}_{12} \\
\delta_{12}\end{array}$ & $\begin{array}{c}\mathbf{g}_{13} \\
\delta_{13}\end{array}$ & $\stackrel{\mathbf{g}}{14}_{\delta_{14}}$ & $\begin{array}{l}\mathbf{g}_{21} \\
\delta_{21}\end{array}$ & $\stackrel{\mathbf{g}}{22}_{\delta_{22}}$ & $\begin{array}{l}\mathbf{g}_{23} \\
\delta_{23}\end{array}$ & $\stackrel{\mathbf{g}_{24}}{\delta_{24}}$ \\
\hline 1 & $\mathrm{C}_{0}$ & 5 & 9 & 13 & 18 & 4 & 8 & 10 & 2 \\
\hline 2 & $\mathrm{C}_{1}$ & 309 & 790 & 3196 & 8353 & 299 & 986 & $\begin{array}{c}320 \\
6\end{array}$ & 9428 \\
\hline 3 & $\mathrm{C}_{2}$ & $\begin{array}{l}5.0 \times \\
10^{-3}\end{array}$ & $\begin{array}{l}2.04 \\
\times 10^{-3}\end{array}$ & $\begin{array}{c}5.30 \times \\
10^{-4}\end{array}$ & $\begin{array}{l}2.19 \\
\times 10^{-4}\end{array}$ & $\begin{array}{l}7.02 \\
\times 10^{-3}\end{array}$ & $\begin{array}{l}2.97 \\
\times 10^{-3}\end{array}$ & $\begin{array}{c}6.0 \\
\times 10 \\
-4\end{array}$ & $\begin{array}{c}3.6 \times 1 \\
0^{-4}\end{array}$ \\
\hline 4 & $\mathrm{C}_{3}$ & 1.51 & 4.36 & 7.48 & $\begin{array}{c}11.9 \\
9\end{array}$ & 2.35 & 5.29 & $\begin{array}{c}9.6 \\
7\end{array}$ & 13.12 \\
\hline
\end{tabular}

\section{Discussion on the results}

The optimization of total cost verses tolerance of the Piston and cylinder assembly, for each case of the design constraint was carried out for 100 generations on a P-IV personal computer using MATLAB 7.5 version the results are shown in tables 2-5 and also represented in figures 5 and 6.

Table 2 Optimal tolerances allocated using genetic algorithm - Worst case Method.

\begin{tabular}{|l|c|c|c|c|}
\hline \multicolumn{2}{|c|}{$\begin{array}{c}\text { Tolerances for } \\
\text { Piston }\end{array}$} & \multicolumn{2}{|c|}{$\begin{array}{c}\text { Tolerances for } \\
\text { Cylinder bore }\end{array}$} & $\begin{array}{c}\text { Least total cost } \\
\text { (Manufacturing cost+ } \\
\text { Asymmetric quality loss) }\end{array}$ \\
\hline$\delta_{11}$ & 0.0170 & $\delta_{21}$ & 0.0170 & \\
\hline$\delta_{12}$ & 0.0040 & $\delta_{22}$ & 0.0045 & \multirow{2}{*}{$\$ 55.88$} \\
\hline$\delta_{13}$ & 0.0021 & $\delta_{23}$ & 0.0024 & \\
\hline$\delta_{14}$ & 0.0012 & $\delta_{24}$ & 0.0010 & \\
\hline
\end{tabular}

The Figure 5 reflects the general behavior of Genetic algorithm. Problem setup and results of the algorithm has been presented in figure 6 . From these figure 5 and 6 it is clearly understood that how GA is the optimum total machining cost and asymmetric quality loss cost as determined from the genetic algorithm model will be $\$ 55.8845$.

The result indicates that the minimum total cost of the assembly is lowest with Greenwood and Chase method and highest with RSS method. Table 6 shows the comparison of total machining cost with total cost for 
Worst case method. The total cost obtained in this paper is very less, through it includes asymmetric quality loss with machining cost. The Figure7, 8and 9 shows the comparison for different trail run of the complex method, Simulated annealing and genetic algorithm respectively.

\section{Conclusion}

In this paper, focus has been on the optimization of manufacturing cost and quality loss for a simple linear assembly model. GA has been implemented to find the optimized total cost. In this problem exponential model has been used to find the manufacturing cost.

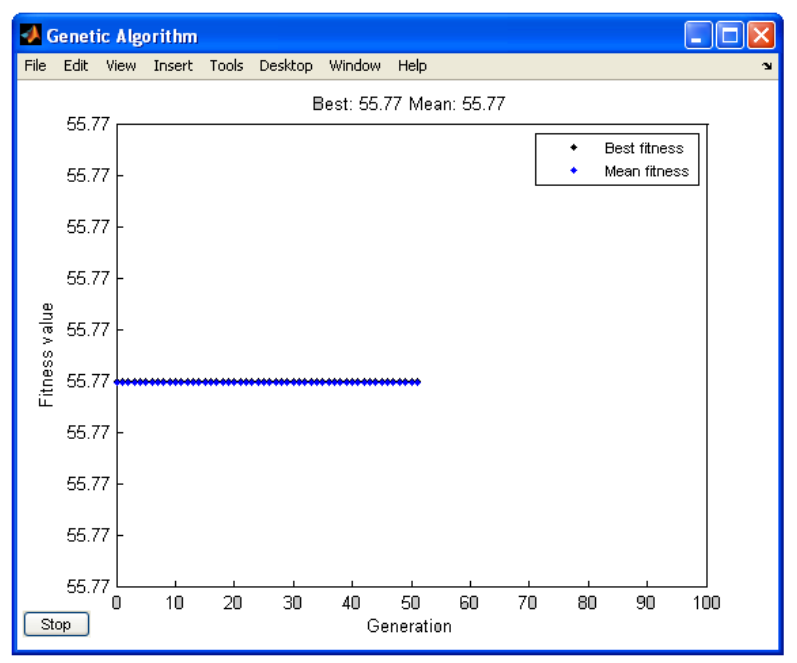

Figure 5 Manufacturing costs associated with feasible solutions of the algorithm.

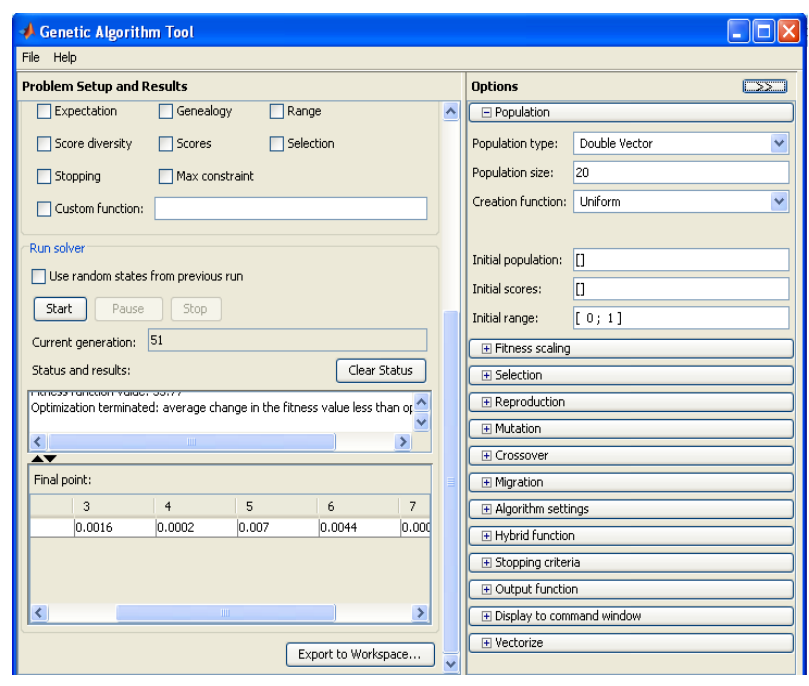

Figure 6 work Setup and results.
Table 3 Optimal tolerances allocated using

Genetic Algorithm - RSS Method

\begin{tabular}{|l|c|c|c|c|}
\hline \multicolumn{2}{|c|}{$\begin{array}{c}\text { Tolerances for } \\
\text { Piston }\end{array}$} & $\begin{array}{c}\text { Tolerances } \\
\text { for Cylinder } \\
\text { bore }\end{array}$ & $\begin{array}{c}\text { Least total cost } \\
\text { (Manufacturing cost+ } \\
\text { Asymmetric quality loss) }\end{array}$ \\
\hline$\delta_{11}$ & 0.0174 & $\delta_{21}$ & $\begin{array}{c}0.017 \\
4\end{array}$ & \\
\hline$\delta_{12}$ & 0.0020 & $\delta_{22}$ & $\begin{array}{c}0.004 \\
5\end{array}$ & \multirow{2}{*}{$\$ 54.94$} \\
\hline$\delta_{13}$ & 0.0007 & $\delta_{23}$ & $\begin{array}{c}0.002 \\
3\end{array}$ & \\
\hline$\delta_{14}$ & 0.0004 & $\delta_{24}$ & $\begin{array}{c}0.001 \\
0\end{array}$ & \\
\hline
\end{tabular}

Table 4 Optimal tolerances allocated using Genetic Algorithm - Spotts Method

\begin{tabular}{|l|c|c|c|c|}
\hline \multicolumn{2}{|c|}{$\begin{array}{c}\text { Tolerances } \\
\text { for Piston }\end{array}$} & \multicolumn{2}{|c|}{$\begin{array}{c}\text { Tolerances for } \\
\text { Cylinder bore }\end{array}$} & $\begin{array}{c}\text { Least total cost } \\
\text { (Manufacturing cost+ } \\
\text { Asymmetric quality } \\
\text { loss) }\end{array}$ \\
\hline$\delta_{11}$ & 0.0173 & $\delta_{21}$ & 0.0170 & \\
\hline$\delta_{12}$ & 0.0020 & $\delta_{22}$ & 0.0046 & \multirow{2}{*}{$\$ 55.34$} \\
\hline$\delta_{13}$ & 0.0006 & $\delta_{23}$ & 0.0022 & \\
\hline$\delta_{14}$ & 0.0003 & $\delta_{24}$ & 0.0009 & \\
\hline
\end{tabular}

Table 5 Optimal tolerances allocated using genetic algorithm - Greenwood and Chases Method

\begin{tabular}{|l|l|l|l|c|}
\hline \multicolumn{2}{|c|}{$\begin{array}{c}\text { Tolerances } \\
\text { for Piston }\end{array}$} & \multicolumn{2}{|c|}{$\begin{array}{c}\text { Tolerances } \\
\text { for Cylinder } \\
\text { bore }\end{array}$} & $\begin{array}{c}\text { Least total cost } \\
\text { (Manufacturing cost+ } \\
\text { Asymmetric quality } \\
\text { loss) }\end{array}$ \\
\hline$\delta_{11}$ & 0.0171 & $\delta_{21}$ & 0.0169 & \\
\hline$\delta_{12}$ & 0.0039 & $\delta_{22}$ & 0.0044 & \multirow{2}{*}{$\$$} \\
\hline$\delta_{13}$ & 0.0020 & $\delta_{23}$ & 0.0023 & \\
\hline$\delta_{14}$ & 0.0011 & $\delta_{24}$ & 0.0009 & \\
\hline
\end{tabular}


Table 6 Comparison Optimum total machining cost With total cost for worst method.

\begin{tabular}{|c|c|c|c|c|}
\hline $\begin{array}{c}\text { Run } \\
\text { No }\end{array}$ & \multicolumn{3}{|c|}{ Total Machining cost } & $\begin{array}{c}\text { Total Cost } \\
\text { (Machining } \\
\text { cost }+ \\
\text { Asymmetric } \\
\text { quality loss) }\end{array}$ \\
\hline & $\begin{array}{c}\text { Genetic } \\
\text { Algorithms }\end{array}$ & $\begin{array}{c}\text { Simulated } \\
\text { annealing }\end{array}$ & $\begin{array}{c}\text { Complex } \\
\text { method }\end{array}$ & $\begin{array}{c}\text { Genetic } \\
\text { algorithm }\end{array}$ \\
\hline 1 & 66.91 & 67.24 & 71.09 & 55.88 \\
\hline 2 & 66.91 & 67.23 & 71.06 & 55.94 \\
\hline 3 & 66.91 & 67.21 & 71.00 & 55.74 \\
\hline 4 & 66.91 & 67.27 & 71.06 & 55.78 \\
\hline 5 & 66.91 & 67.25 & 71.03 & 55.98 \\
\hline
\end{tabular}

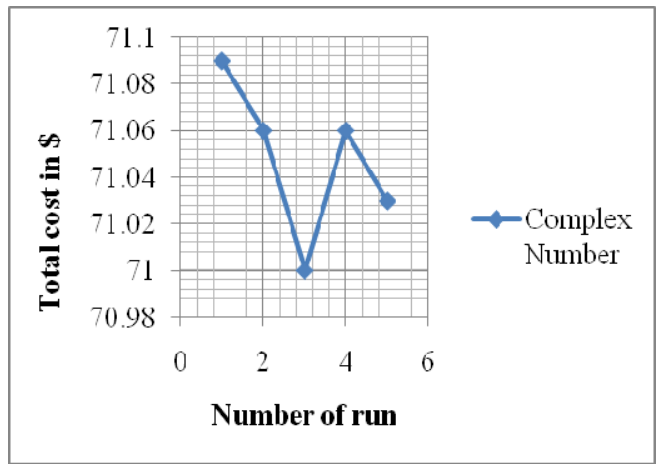

Figure 7 Comparison of total cost with number of trial run for Complex numbers

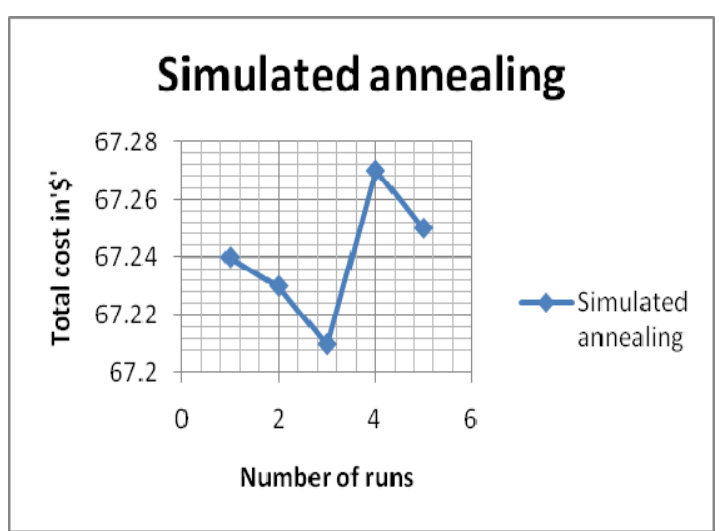

Figure 8 Comparison of total cost with number of trial run for Simulated annealing

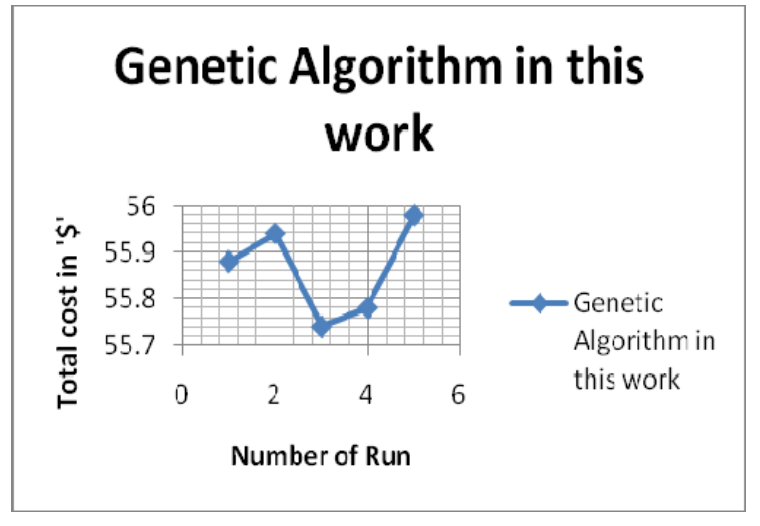

Figure 9 Comparison total cost with number of trial run for Genetic algorithm.

The GA method is very efficient and effective and it is simple and easy to implement.

In this paper, exponential model has been adopted to find the manufacturing cost and asymmetric quality loss by training the algorithm. A better model may be approached for different assembly problems to find the optimized cost using different optimization techniques.

\section{Notation}

$c_{i} \quad$ - Coefficients used in Machining cost unction;

$c_{m} \quad$ - Total machining cost for the components;

$C_{r} \quad$ - Cost of casting process;

$g(\delta)$ - Machining cost function;

$g_{i j k}(\delta)$ - Machining cost - tolerance model;

$\delta \quad$ - Machining tolerance parameter;

$\delta_{i j} \quad$ - Machining tolerance for part i and process $\mathrm{j}$;

$\delta_{i j d} \quad$ - Design tolerance on dimension chain;

\section{Acknowledgements}

The authors are very much grateful to the anonymous expert referees for giving useful suggestions to improve this manuscript. 


\section{Reference}

1. M.D. Al-Ansary, I.M.Delab, concurrent optimization of Design and Machining Tolerances using the Genetic Algorithms method, International journal of machine tools and manufacture, 37(12), (1997), 17211731.

2. Chin-chun.Wu, Zhuoning Chen, Geo-Ry Tong, Component Tolerance Design for minimum Quality loss and manufacturing cost, International journal of computers in industry, 35, (1998), 223-232.

3. S.Ch. Dimitrellou, S.C. Diplaris, M.M. Sfantsikopoulos, Cost-competent tolerancing in CAD, International journal of advanced manufacturing technology, (2006).

4. Herbert Moskowitz, Robert Plante, Jeff Duffy, multivariate tolerance design using quality loss, IIE Transactions, 33, (2001), 437-448.

5. M.F. Huang, Y.R. Zhong, Z.G. Xu, Concurrent process tolerance design based on minimum Product manufacturing cost and quality loss, International Journal of advanced manufacturing technology, 25, (2005), 714-722.

6. A. Jeang, An approach of tolerance design for quality improvement and cost reduction, International journal of production research, 35 (5), (1997), 1193-1211.

7. M.H.C. Li, Quality loss function Based Manufacturing process setting models for Unbalanced Tolerance Design, International journal of advanced manufacturing Technology, 16, (2000), 39- 45.

8. A. Noorul Haq, M. Siva kumar, R. Saravanan, V. Muthiah, Tolerance design optimization of Machine elements using genetic algorithm, International journal of advanced manufacturing technology, 25, (2005), 385-391.

9. G. Prabhaharan, P. Asokan, P.Ramesh, S. Rajendran, Genetic-algorithm-based optimal Tolerance allocation using a least-cost model, International journal of advanced manufacturing technology, 24, (2004), 647660.

10. S. Rajasekaran, G.A. Vijayalakshmi pai, "Neural networks, Fuzzy logic, and Genetic Algorithms synthesis and Applications", Prentice Hall of India private limited, (2007).

11. Saeed Maghsoodloo, Ming-Hsien Caleb Li, Optimal asymmetric tolerance design, IIE Transactions, 32, (2000), 1127-1137.

12. P.K. Singh, P.K. Jain, and S.C. Jain, Simultaneous Optimal selection of design and manufacturing tolerances with different stack up conditions Using Genetic algorithm, International journal of production research, 41 (11), (2003), 2411-2429.

13. P.K. Singh, P.K. Jain, and S.C. Jain, A genetic algorithm-based solution to optimal tolerance Synthesis of mechanical assemblies with alternative manufacturing processes: focus on Complex tolerancing problems, International journal of production research, 42 (24), (2004), 5185-5215.

14. Ta-Cheng Chen, Gary W. Fischer, A GA-based search method for the tolerance allocation Problem, International journal of artificial intelligence in engineering 14 (2000), 133-141.

15. C.C. Wu, G.R. Tang, Tolerance design for products with asymmetric quality losses, International Journal of production research, 36 (9), (1998), 2529-2541.

16. K.W. Chase, W.H. Greenwood, B.G. Loosli, and L.F. Hauglund, Least cost tolerance allocation for mechanical assemblies with automated process selection. manuf. Rev, 3(1), (1990), 49-59.

17. M.Y. Nagarwala, P.S. Pulat, and S.R. Raman, Process selection and tolerance allocation for minimum cost assembly. International journal manuf. Sci. Eng., 68 (1), (1994), 47-55.

18. C. Zhang, and H.P. Wang, Integrated tolerance optimization with simulated Annealing. International journal of manufacturing technology, 8, (1993), 167174

19. G. Zhang, Simultaneous tolerancing for design and manufacturing. International journal of production research, 34, (1996), 3361-3382.

20. R. Soderberg, Tolerance allocation considering customer and manufacturing Objectives, Advanced design automation, DE-65-2, (1993), 149-157.

21. C. Feng, and A. Kusiak, Robust tolerance design with the integer programming Approach.Trans. ASME, Journal of manufacturing science engineering, 119, (1997), 603-610.

22. A. Jeang, A., Economic tolerance design for quality, Quality reliability engineering in industries, 11, (1995), 113-121.

23. B.Ye, and F.A. Salustri, F.A., Simultaneous tolerance synthesis for manufacturing and quality, Research in engineering design, 14(2), (2004), 98-106.

24. S.D. Nigam, and J.D. Turner, Review of statistical approaches to tolerance analysis. CAD, 27(1), (1995), 6-15.

25. Chi Zhou, Liang Gao, Hai-Bing Gao, and Kun Zan, Particle Swarm Optimization for Simultaneous optimization of design and machining tolerances, SEAL 2006, LNCS 4247 (Springer-Verlag Berlin Heidelberg ), pp. $873-880$.

26. G. Prabhaharan, R. Ramesh, P. Asokan, Concurrent optimization of assembly tolerances for quality with position control using scatter search approach, International journal of production research,vol. 45(21), (2006), 4959- 4988.

27. R. Sampath Kumar, V. Soundararajan, N. Alagumurthi, Review of Tolerance analysis, allocation and constraints in Manufacturing, International journal of manufacturing science and production, Vol.10(1), (2009), 1-16. 